\title{
An assessment of the stray light in 25 years of Dobson total ozone data at Athens, Greece
}

\author{
J. Christodoulakis ${ }^{1}$, C. Varotsos ${ }^{1}$, A. P. Cracknell ${ }^{2}$, C. Tzanis ${ }^{1}$, and A. Neofytos ${ }^{1}$ \\ ${ }^{1}$ Division of Environmental Physics and Meteorology, Faculty of Physics, University of Athens, Athens, Greece \\ ${ }^{2}$ Division of Electronic Engineering and Physics, University of Dundee, Dundee, UK \\ Correspondence to: J. Christodoulakis (ichristo@phys.uoa.gr)
}

Received: 24 November 2014 - Published in Atmos. Meas. Tech. Discuss.: 18 February 2015

Revised: 8 July 2015 - Accepted: 9 July 2015 - Published: 30 July 2015

\begin{abstract}
In this study, we investigated the susceptibility of the Dobson spectrophotometer No. 118 to stray light interference. In this regard, a series of total ozone content measurements were carried out in Athens, Greece for airmass values $(\mu)$ extending up to $\mu=5$. The monochromaticheterochromatic stray light derived by Basher's model was used in order to evaluate the specific instrumental parameters which determine if this instrument suffers from this problem or not. The results obtained indicate that the measurements made by the Dobson instrument of the Athens station for air mass values up to 2.5 , underestimates the total ozone content by $3.5 \mathrm{DU}$ in average, or about $1 \%$ of the station's mean total ozone content (TOC). The comparison of the values of the same parameters measured 15 years ago with the present ones indicates the good maintenance of the Dobson spectrophotometer No. 118. This fact is of crucial importance because the variability of the daily total ozone observations collected by the Athens Dobson Station since 1989 has proved to be representative to the variability of the mean total ozone observed over the whole mid-latitude zone of the Northern Hemisphere. This stresses the point that the Athens total ozone station, being the unique Dobson station in south-eastern Europe, may be assumed as a ground truth station for the reliable conversion of the satellite radiance observations to total ozone measurements.
\end{abstract}

\section{Introduction}

The Dobson spectrophotometer was the very first instrument developed in the early 1920s by G. M. B. Dobson to study the circulation in the upper atmosphere through the ozone move- ments (Dobson, 1957, 1968a). Since the first instrument was constructed, a number of instruments were placed around the world at selected stations that began measurements of total ozone content (TOC) on a daily basis. Since then, a long time series of TOC data was created. A worldwide network of instruments was established during the International Geophysical Year (July 1957-June 1958) in order to better understand and study the atmospheric ozone (Broennimann et al., 2003). Even though newer and more sophisticated instruments were since created, i.e. Brewer spectrophotometer, the Dobson spectrophotometer is still used and is considered a key part of the ground-based monitoring system of the ozone layer (Bojkov and Balis, 2009; Varotsos and Cracknell 1994a,b; Varotsos et al., 1995, 2012a; Chandra and Varotsos, 1995; Varotsos, 1998).

The fact that the earliest studies and the preliminary data records of TOC were made using the Dobson spectrophotometer it makes this instrument a reference device for TOC data obtained by other ground-based and satellite borne instrumentation. As a result, any new device, on board a satellite or ground-based, that is constructed for TOC measurements is validated against Dobson which is considered as a standard instrument (Bernhard et al., 2003; McPeters et al., 2008; Cracknell and Varotsos, 2009, 2012, 2014; Varotsos et al., 2014; Tzanis, 2005, 2009). So, it is important to understand and study all sources of errors in Dobson instrument operations that could lead to a false measurement or miscalculation of TOC.

In brief, the Dobson spectrophotometer uses the differential absorption between two wavelengths of the solar ultraviolet spectrum, which together compose one band pair. One of the wavelengths of each band pair is being absorbed (e.g. 
beam $i$ ) by the ozone in the atmosphere, while the other is not (e.g. beam $j$ ). Within the instrument, the two beams $i$ and $j$ follow different optical paths. At first, total solar light enters the instrument and is directed to a monochromator so that the two beams $i$ and $j$ can be isolated. Beam $i$ is then driven directly to another monochromator and then to a photomultiplier. Beam $j$ follows a slightly different path. After the first monochromator, the beam $j$ passes through an optical wedge which has a different absorption factor at each point and its position is controlled by the user through a graduated dial. Then, the beam $j$ follows the same path as the beam $i$ and arrives at photomultiplier. When the pulsating electric current, that the photomultiplier generates, is zero the beam $j$ has been absorbed by the wedge exactly as the beam $i$ has been absorbed by the ozone in the atmosphere. Knowing the exact position of the wedge the TOC in the atmosphere can be calculated. A detailed description of the principles of measurement and the operation of the instrument is available elsewhere (Cracknell and Varotsos, 2012; Komhyr and Evans, 2008).

Apart from the absorption of radiation passing through the atmosphere by ozone there is also the scattering by aerosol particles and Rayleigh scattering (Varotsos et al., 2012b). The effect of the latter on the radiation is corrected by using appropriate factors during the processing of the measurements. In order to eliminate the attenuation caused by aerosol particles, two band pairs are used for a single measurement of TOC. More details of the procedure can be found elsewhere (Komhyr and Evans, 2008). The band pairs that are used most widely and hence for the experiment presented in the next sections are $\mathrm{A}$ and $\mathrm{D}$, where the $\mathrm{A}$ band pair consists of 305.5 and $325.0 \mathrm{~nm}$ beams, while the $\mathrm{D}$ band pair consists of 317.5 and $339.9 \mathrm{~nm}$ beams.

Currently there are about 50 Dobson instruments that constitute the global Dobson network. In order to maintain these instruments and ensure their continuing well-functioning, they are involved in regular validation/calibration campaigns. During these campaigns, among other activities, these instruments are used for taking simultaneous measurements with a reference Dobson (Christodoulakis et al., 2008; Tzanis et al., 2009; Varotsos and Kondratyev, 1995). The goals are to evaluate the performance of a particular Dobson instrument against the reference one and to transfer the calibration level of the reference instrument to the examined one. Besides these campaigns each station performs regular tests that are designed to determine whether the instrument is operating within the required limits for the accuracy and stability.

There are circumstances though in which an instrument fails to determine accurately the amount of total ozone, not because of instrumental malfunction but rather from the limitations in the optical design of the instrument (Dobson, 1968b). Specifically, high solar zenith angle measurements are problematic. Major problems can be triggered by the following sources.
- Unwanted sky light from around the sun could enter the instrument (sky light error).

- The light of long wavelengths that is scattered within the instrument could be combined with the light of short wavelength used for the measurement (internal stray light error).

- Apart from the direct sunlight (used for the measurement), the light component by multiple scattering in the atmosphere (atmospheric scattered light error; Dobson, 1968b; Evans et al., 2009).

The first limitation refers to the angular distribution of diffused radiation. Specifically, around the sun there is an area where an intensity maximum is observed. This phenomenon is explained by the scattering function. According to this function, a maximum is observed in forward direction which leads to this intensity maximization (Kondratyev, 1969). The third limitation refers to the contribution of the spectral component of the solar light originating outside the band pass of the instrument since the out-of-band light is not completely removed by the slits, and thus it is measured by the instrument. The dependence of this contribution on the optical path of the light (solar zenith angle and amount of ozone) creates the non-linear error in the retrieved total ozone that appears as diurnal variability in the total column ozone measurements.

Focusing on the stray light, its presence in the Dobson instrument leads to lower TOC values as the air mass increases (e.g. Labow et al., 2004; McPeters and Labow, 1996). More specifically, if air mass reaches the value 3 then the stray light results in a significant underestimation of the TOC measurements. This underestimation in TOC becomes stronger under conditions of high optical path length (e.g. high TOC). It should be emphasized that the stray light also affects TOC measurements for air mass values less than 3 but not to such an extent as for air mass values greater than 3 . This is because of the previously mentioned "internal stray light error" which is still present even for small solar zenith angles (Dobson, 1968b).

It is worthwhile to note that the slit widths adopted by Dobson (1931) were not very narrow thus preventing stray light of other wavelengths from falling on the photomultiplier. According to Basher (1982), for direct AD measurements, errors of 1,3 and $10 \%$ may be present at air mass values of $2.5,3.2$ and 3.8 , respectively. This is a permanent problem for instruments operating in high latitudes but also affects ozone vertical profile (Umkehr) measurements performed by using the Dobson spectrophotometer (e.g. Petropavlovskikh et al., 2009, 2011).

The term "stray light" describes the part of the radiation in a beam, which was not part of it from the beginning, but has contaminated it due to scattering. It should be stressed that this extra radiation may be due to scattering outside the instrument (external), i.e. during sun light propagation 
through the atmosphere (sky light error, atmospheric scattered light error) or scattering within the instrument (internal) (see point (3) and (1) in Sect. 3.4 of Scarnato et al., 2012, respectively). The external stray light includes both wavelengths which are normally measured from the instrument (homochromatic stray light) and wavelengths different from the desired ones (heterochromatic stray light) which can not be totally rejected by the instrument. Especially for the case of Dobson spectrophotometer which has a wide field of view, about $8^{\circ}$ (Staehelin et al., 2003), this kind of stray light is important. The internal stray light is due to the large number of the optical surfaces (28 or 32 optical surfaces, depending on the instrument), which are used in a Dobson spectrophotometer; this stray light consists mostly of heterochromatic radiation (Basher, 1982). In other words, the stray light effect varies from instrument to instrument and each Dobson instrument has a unique signature to stray light (Olafson and Asbridge, 1981). It should be also noticed that stray light affects both direct sun and zenith blue observations (Evans et al., 2009).

Basher (1982) created a monochromatic, heterochromatic stray light model in order to estimate stray light levels present in the measurements of a particular instrument. This model uses two parameters that determine whether or not an instrument suffers from this problem. This model has been employed in the present paper, and it is presented in more detail in the next sections along with the experiments and the analysis performed in order to address the question of whether or not the Dobson spectrophotometer No. 118 installed in Athens since 1989 suffers from stray light error. It is worthwhile to note that this instrument was also checked for stray light levels about 15 years ago (Varotsos et al., 1998). The combination of the new levels of stray light with the previously detected ones will enable a re-calculation of the longterm time series and the reduction of the inaccuracies of the Athens Dobson Station TOC measurements, which according to the literature (e.g. Chandra et al., 1996) tracks the seasonal trends of TOC as they are estimated using averaged data for different latitudinal zones of the mid-latitudes of the Northern Hemisphere.

\section{Basher's model and other efforts}

The stray light contribution mainly affects the short wavelength beam of the band pairs measured by a Dobson spectrophotometer. This causes the log intensity ratio vs. air mass function to deviate from linearity. The latter generates two errors which are schematically presented in Fig. 1 (Basher, 1982). The first error (referred to as $\Delta X$ ) is the reduction of the $\log$ intensity ratio with air mass which results in reduced TOC values. The second error (referred to as $\triangle E T C$ ) is the overestimation of the extraterrestrial constant (ETC) that should be determined using log intensity ratio vs. air mass data. This error makes the residual curvature in the data seem

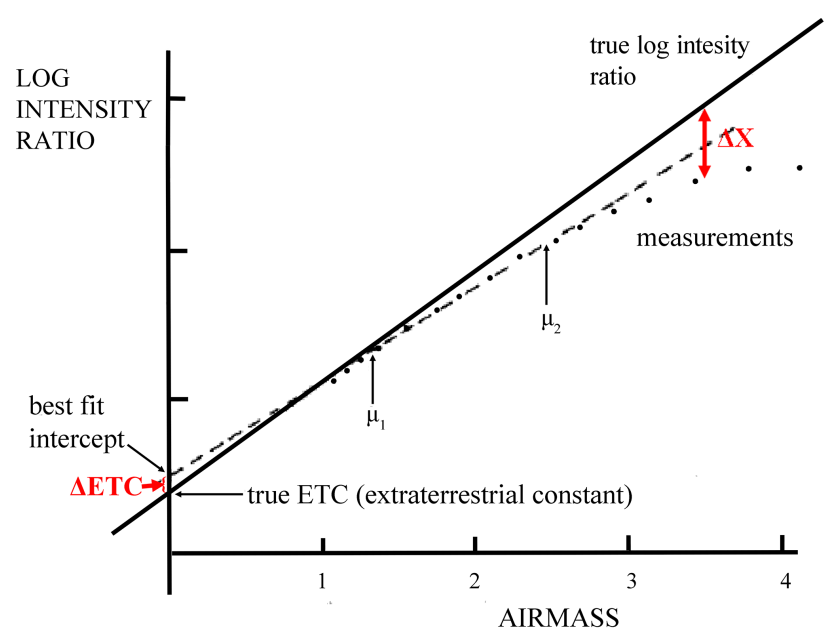

Figure 1. Schematic presentations of the stray light errors induced on $\log$ intensity ratios $(\Delta X)$ and on the determination of extraterrestrial constants ( $\triangle \mathrm{ETC})$ (Basher, 1982; modified).

small and the TOC measurements constant with air mass, but this may conceal a systematic negative error in the TOC measurements (Basher, 1982).

In order to investigate the aforementioned errors Basher (1982) proposed a monochromatic, heterochromatic stray light model. According to this model stray light levels are determined by calculating two parameters $R_{0}$ and $\alpha . R_{0}$ is defined as the ratio of the energy of the monochromatic stray light source to the energy of the desired band and would be measured for zero air mass. Its values range from $10^{-5}$ to $10^{-3}$ and the smaller it is, the less affected the instrument is to stray light interference. $\alpha$ is the ratio of the attenuation coefficient of the stray light band to that of the desired band. Its values range from 0.7 to 1.2 , and the greater it is, the greater the influence of stray light on TOC measurements.

The equations for the estimations of $\triangle \mathrm{ETC}$ and $\Delta X$ are as follows:

$$
\begin{aligned}
& \Delta \mathrm{ETC}=\frac{1}{\mu_{2}-\mu_{1}} \log \frac{\left(1+R_{0} 10^{\mu_{2} \alpha}\right)^{\mu_{1}}}{\left(1+R_{0} 10^{\mu_{1} \alpha}\right)^{\mu_{2}}}, \\
& \Delta X=\frac{-1}{\mu \Delta \alpha}\left(\Delta \mathrm{ETC}+\log \left(1+R_{0} 10^{\mu \alpha}\right)\right),
\end{aligned}
$$

where $\mu_{1}$ and $\mu_{2}$ are the abscissas of the points where the straight line used for determining ETC intersects the log intensity-air mass curve and $\Delta \alpha$ is the band pair's ozone absorption coefficient (the values of $\mu_{1}$ and $\mu_{2}$ used in this study were 1.0 and 2.5 , respectively). The $\mu_{1}$ value is the theoretically smallest value of the air mass, while $\mu_{2}$ value is considered as the largest value of air mass for which the most reliable band pairs A and D can be used (Dobson, 1957).

The procedure for using this model in order to specify the parameters $R_{0}$ and $\alpha$ for a particular Dobson spectrophotometer is firstly to make a series of observations for a range of values of air mass (experimental data). Then, $\triangle \mathrm{ETC}$ and 

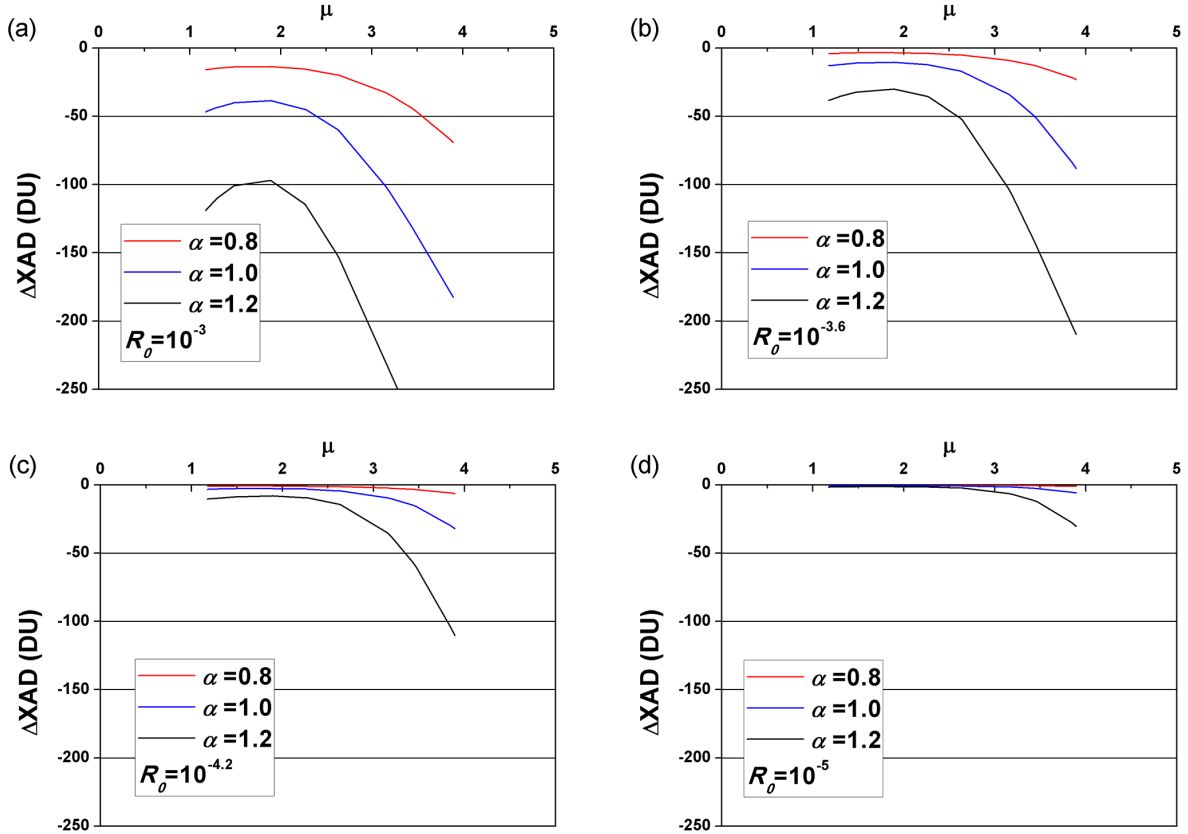

Figure 2. Variation of ozone error $\Delta X \mathrm{AD}$ as a function of air mass $\mu$, for various values of parameters $R_{0}$ and $\alpha$ of the Basher model and for air masses $\mu_{1}=1.0$ and $\mu_{2}=2.5$.

Table 1. Dates of the experiment and air mass ranges.

\begin{tabular}{ll}
\hline Date & Air mass range \\
\hline 5 September 2012 & $1.174-3.894$ \\
24 September 2012 & $1.281-5.045$ \\
29 September 2012 & $1.344-5.048$ \\
30 September 2012 & $1.327-4.358$ \\
31 October 2012 & $1.626-4.058$ \\
\hline
\end{tabular}

$\Delta X$ are calculated using Eqs. (1) and (2) for different values of $R_{0}$ and $\alpha$. Afterwards, the obtained $\Delta X$ values are added to the TOC value of the particular day. These theoretical results are compared with the experimental data in order to estimate the values of $R_{0}$ and $\alpha$ for which the best fit is achieved.

Still another method is under development to assess stray light contribution to Dobson measurements as described in paper by Evans et al. (2009). The main idea behind this study was presented by Dobson who suggested that if the component of the electrical signal generated from photomultiplier tube due to unwanted radiation (stray light) can be measured, then the obtained measurements can be corrected using an appropriate formula (Dobson, 1968b). Evans and his team figure out that in order to apply this correction procedure, they should remove the desired wavelengths measured by the instrument using external filters. In order to conduct the experiment, a Dobson instrument was modified in a way that only the short wavelength beam of the band pairs used could be seen by the photomultiplier when a slit mask was pushed in place from outside the instrument. However, the presented results in that paper concerned stray light effect on the measurements obtained using a special technique for the estimation of ozone profile (Umkehr measurements) and not for the estimation of TOC. In addition, prior to the implementation of this method some problems, like the necessary extensive modification of the instrument and the need of experienced operator to implement this, have to be tackled (for more details please see Evans et al., 2009).

\section{Measurements and results}

In order to determine stray light error for Dobson No. 118 we collected a series of direct sun $\mathrm{AD}$ wavelength pairs measurements. Measurements were collected over a large range of solar zenith angles during 5 clear-sky days in SeptemberOctober 2012. For further details see Table 1.

The results of the experiment are summarized in Fig. 2. The theoretically estimated errors (Eq. 2) are plotted as a function of air mass. Results vary based on the selected values of $R_{0}$ and $\alpha$. It is obvious from these figures that as $R_{0}$ reduces, all the curves (i.e. $\Delta X$ error values) tend to be zero, even in the case of large $\alpha$. So we can infer that the smaller the parameter $R_{0}$, the more capable the specific spectrophotometer is to reject the scattered radiation. As far as the parameter $\alpha$ is concerned we conclude, based on the same figure, that as its value increases, the influence of the stray light in the TOC measurements increases too. 

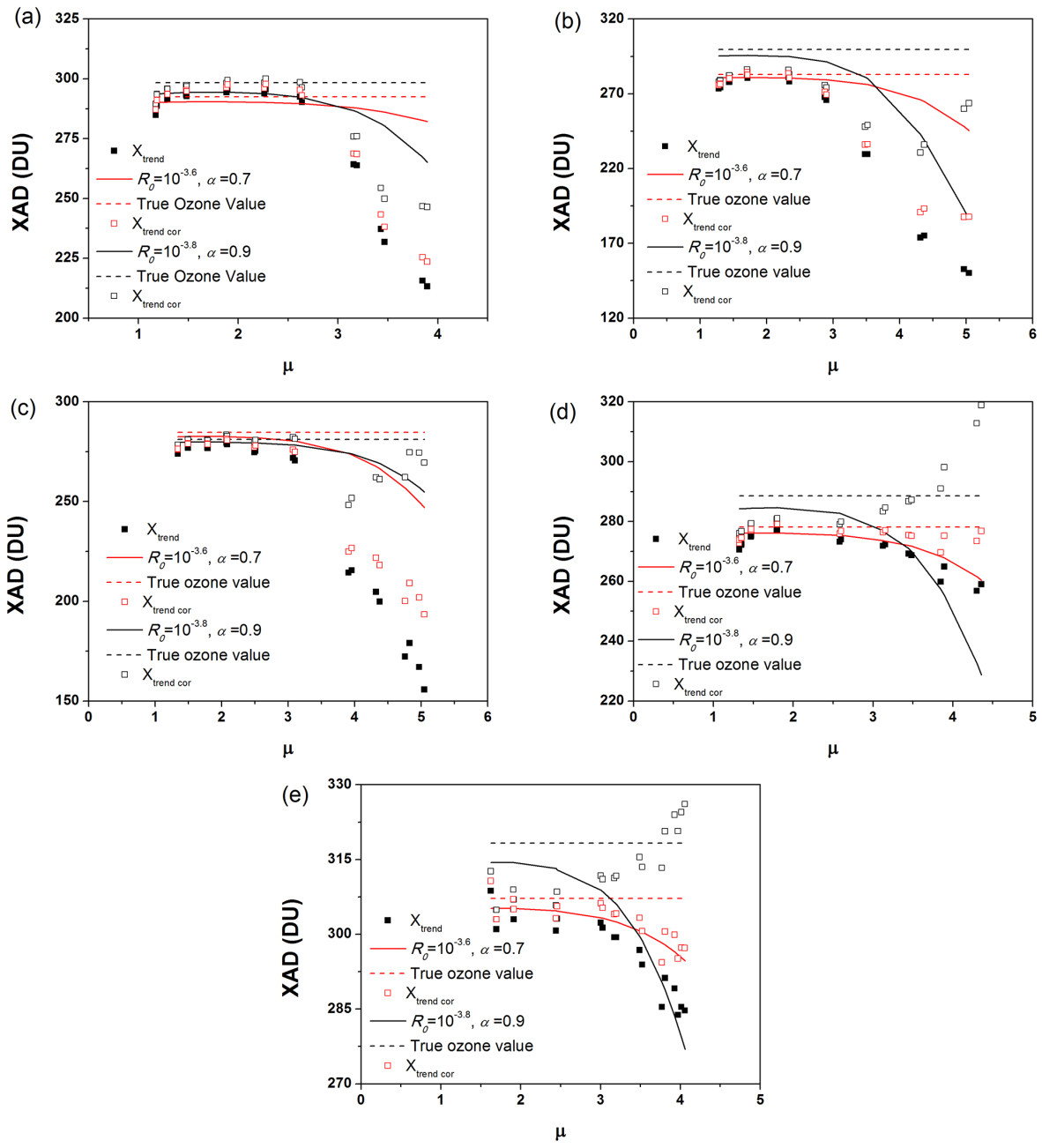

Figure 3. Comparison of experimental data (black dots) with stray light model applied for two different sets of parameters $R_{0}$ and $\alpha$ (solid lines) along with the corresponding true ozone values (dashed lines). Empty dots, red and black, represent the corrected measurements using the values $R_{0}=10^{-3.6}, \alpha=0.7$ and $R_{0}=10^{-3.8}, \alpha=0.9$, respectively. The presented pairs of $R_{0}, \alpha$ and the corresponding true ozone value have been picked out by the final obtained results. (a) 5 September 2012, (b) 24 September 2012, (c) 29 September 2012, (d) 30 September 2012 and (e) 31 October 2012. Model was executed for values of air mass $\mu_{1}=1.0$ and $\mu_{2}=2.5$.

Total column ozone data deduced from AD-pair measurements are plotted as a function of air mass, separately for 5 days (Fig. 3). Observations are compared with the theoretical stray light model results. Model parameters are provided in each panel legend. In this figure, the corrected measurements for the case of $R_{0}$ and $\alpha$ values are also presented. The procedure of fitting the stray light model to the observations is described in the next paragraph. As can be noted by Fig. 3, the model does not succeed in describing each day's observations for a particular pair of $R_{0}$ and $\alpha$. This behaviour could be interpreted by the fact that the calculated errors "are very dependent" on the model conditions, i.e. the values of the four parameters that model relies on $\left(\mu_{1}, \mu_{2}, R_{0}\right.$ and $\alpha$ ), the general operating conditions under which ozone measurements are made along with the lack of knowledge about the propagation of unwanted radiation within the instrument (Basher, 1982).

In order to evaluate Basher's model parameters for Dobson No. 118 the following analytical steps were accomplished.

1. For each day TOC observations were conducted for various air mass values. The measurements obtained constitute the experimental TOC values (referred to as $\left.X_{\text {trend }}\right)$.

2. The $\Delta X$ values were calculated by using the Basher's model (see Eq. 2) for $R_{0}$ ranging from $10^{-3.3}$ to $10^{-5}$ and $\alpha$ ranging from 0.7 to 1.2 . The air mass values for which TOC observations were conducted at step (1) were used as input values in Eq. (2). In Table 2 is given an example of the $\Delta X$ values calculated for the 
Table 2. $\Delta X$ values calculated by Basher's model for the case of 5 September 2012 for $R_{0}=10^{-3.8}$ and all $\alpha$ values $\left(\mu_{1}=1.0\right.$ and $\mu_{2}=2.5$ ).

\begin{tabular}{lrrrrrr}
\hline \multicolumn{7}{c}{$\Delta X$ values (DU) } \\
\hline \multicolumn{7}{c}{1.0 .9} \\
\cline { 2 - 7 } 1.174 & -25.3 & -14.6 & -8.4 & -4.7 & -2.6 & -1.5 \\
1.186 & -25.1 & -14.5 & -8.3 & -4.7 & -2.6 & -1.4 \\
1.187 & -25.1 & -14.5 & -8.3 & -4.7 & -2.6 & -1.4 \\
1.290 & -23.4 & -13.6 & -7.8 & -4.4 & -2.5 & -1.4 \\
1.293 & -23.3 & -13.6 & -7.8 & -4.4 & -2.5 & -1.4 \\
1.480 & -21.2 & -12.4 & -7.1 & -4.1 & -2.3 & -1.3 \\
1.484 & -21.1 & -12.3 & -7.1 & -4.1 & -2.3 & -1.3 \\
1.885 & -19.7 & -11.6 & -6.8 & -3.9 & -2.2 & -1.3 \\
1.894 & -19.7 & -11.6 & -6.8 & -3.9 & -2.2 & -1.3 \\
2.262 & -23.2 & -13.6 & -7.8 & -4.5 & -2.5 & -1.4 \\
2.277 & -23.4 & -13.7 & -7.9 & -4.5 & -2.6 & -1.4 \\
2.619 & -33.9 & -19.4 & -10.9 & -6.0 & -3.3 & -1.8 \\
2.640 & -34.9 & -19.9 & -11.1 & -6.1 & -3.3 & -1.8 \\
3.158 & -74.4 & -42.3 & -22.6 & -11.6 & -5.8 & -2.9 \\
3.190 & -77.9 & -44.4 & -23.7 & -12.1 & -6.1 & -3.0 \\
3.431 & -107.6 & -63.4 & -34.1 & -17.1 & -8.2 & -3.9 \\
3.468 & -112.6 & -66.8 & -36.0 & -18.1 & -8.6 & -4.0 \\
3.847 & -166.8 & -107.4 & -61.4 & -31.1 & -14.4 & -6.3 \\
3.894 & -173.6 & -113.0 & -65.2 & -33.2 & -15.3 & -6.7 \\
\hline
\end{tabular}

Table 3. $X_{\text {true }}$ values for the case of 5 September 2012 for $R_{0}=$ $10^{-3.8}$ and all $\alpha$ values $\left(\mu_{1}=1.0\right.$ and $\mu_{2}=2.5$ ).

\begin{tabular}{lrrrrrr}
\hline & \multicolumn{5}{c}{$X_{\text {true }}(\mathrm{DU})$} \\
\cline { 2 - 7 }$\mu$ & \multicolumn{5}{c}{$\alpha$} \\
\cline { 2 - 7 } 1.174 & 1.2 & 1.1 & 1 & 0.9 & 0.8 & 0.7 \\
1.186 & 314.0 & 303.3 & 297.1 & 293.4 & 291.3 & 290.2 \\
1.187 & 313.8 & 303.2 & 297.0 & 293.4 & 291.3 & 290.1 \\
1.290 & 313.8 & 303.2 & 297.0 & 293.4 & 291.3 & 290.1 \\
1.293 & 312.1 & 302.3 & 296.5 & 293.1 & 291.2 & 290.1 \\
1.480 & 309.9 & 302.3 & 296.5 & 293.1 & 291.2 & 290.1 \\
1.484 & 309.8 & 301.1 & 295.8 & 292.8 & 291.0 & 290.0 \\
1.885 & 308.4 & 300.3 & 295.8 & 292.8 & 291.0 & 290.0 \\
1.894 & 308.4 & 300.3 & 295.5 & 292.6 & 290.9 & 290.0 \\
2.262 & 311.9 & 302.3 & 296.5 & 293.2 & 290.9 & 290.0 \\
2.277 & 312.1 & 302.4 & 296.6 & 293.2 & 291.3 & 290.1 \\
2.619 & 322.6 & 308.1 & 299.6 & 294.7 & 292.0 & 290.5 \\
2.640 & 323.6 & 308.6 & 299.8 & 294.8 & 292.0 & 290.5 \\
3.158 & 363.1 & 331.0 & 311.3 & 300.3 & 294.5 & 291.6 \\
3.190 & 366.6 & 333.1 & 312.4 & 300.8 & 294.8 & 291.7 \\
3.431 & 396.3 & 352.1 & 322.8 & 305.8 & 296.9 & 292.6 \\
3.468 & 401.3 & 355.5 & 324.7 & 306.8 & 297.3 & 292.7 \\
3.847 & 455.5 & 396.1 & 350.1 & 319.8 & 303.1 & 295.0 \\
3.894 & 462.3 & 401.7 & 353.9 & 321.9 & 304.0 & 295.4 \\
\hline True ozone & 343.0 & 321.5 & 307.1 & 298.3 & 293.5 & 291.1 \\
value & & & & & & \\
\hline & & & & & &
\end{tabular}

Table 4. $X_{\text {trend }}$ and $X_{\text {theor }}$ values for the case of 5 September 2012 for $R_{0}=10^{-3.8}$ and all $\alpha$ values $\left(\mu_{1}=1.0\right.$ and $\left.\mu_{2}=2.5\right)$.

\begin{tabular}{lrrrrrrr}
\hline & $X_{\text {trend }}$ & \multicolumn{6}{c}{$X_{\text {theor }}($ DU) } \\
\cline { 3 - 8 }$\mu$ & (DU) & \multicolumn{5}{c}{$\alpha$} \\
\cline { 3 - 8 } & & 1.2 & 1.1 & 1 & 0.9 & 0.8 & 0.7 \\
1.174 & 284.8 & 317.7 & 306.8 & 298.7 & 293.6 & 290.9 & 289.6 \\
1.186 & 288.9 & 318.0 & 306.9 & 298.8 & 293.7 & 290.9 & 289.6 \\
1.187 & 288.7 & 318.0 & 307.0 & 298.8 & 293.7 & 290.9 & 289.6 \\
1.29 & 291.4 & 319.6 & 307.9 & 299.3 & 293.9 & 291.1 & 289.7 \\
1.293 & 291.3 & 319.7 & 307.9 & 299.3 & 293.9 & 291.1 & 289.7 \\
1.48 & 293.2 & 321.9 & 309.1 & 300.0 & 294.3 & 291.2 & 289.8 \\
1.484 & 292.7 & 321.9 & 309.1 & 300.0 & 294.3 & 291.2 & 289.8 \\
1.885 & 294.3 & 323.3 & 309.9 & 300.3 & 294.4 & 291.3 & 289.8 \\
1.894 & 295.5 & 323.3 & 309.8 & 300.3 & 294.4 & 291.3 & 289.8 \\
2.262 & 293.8 & 319.9 & 307.9 & 299.2 & 293.9 & 291.0 & 289.7 \\
2.277 & 295.5 & 319.6 & 307.7 & 299.1 & 293.8 & 291.0 & 289.7 \\
2.619 & 292.5 & 309.1 & 302.1 & 296.2 & 292.3 & 290.3 & 289.3 \\
2.64 & 290.2 & 308.2 & 301.6 & 295.9 & 292.2 & 290.2 & 289.3 \\
3.158 & 264.2 & 268.6 & 279.2 & 284.5 & 286.7 & 287.7 & 288.2 \\
3.19 & 263.8 & 265.1 & 277.1 & 283.4 & 286.2 & 287.5 & 288.1 \\
3.431 & 237.2 & 235.4 & 258.1 & 273.0 & 281.2 & 285.3 & 287.2 \\
3.468 & 231.8 & 230.4 & 254.7 & 271.0 & 280.3 & 284.9 & 287.1 \\
3.847 & 215.6 & 176.2 & 214.1 & 245.7 & 267.2 & 279.2 & 284.8 \\
3.894 & 213.2 & 169.4 & 208.5 & 241.9 & 265.1 & 278.2 & 284.4 \\
\hline
\end{tabular}

case of 5 September 2012 for one of the $R_{0}$ values $\left(R_{0}=10^{-3.8}\right)$ and all $\alpha$ values.

3. For each experimental day, a representative TOC value was calculated according to the usual procedure followed by the station. In the case of 5 September 2012, this value was $288.7 \mathrm{DU}$.

4. Then absolute $\Delta X$ values from step (2) were added to the representative TOC value from step (3). The calculated TOC values are the theoretically expected values of real TOC field if there was no stray light effect (referred to as $\left.X_{\text {true }}\right)$. An example of this table is given in Table 3 for the same day as Table 2 and for the same $R_{0}$ and $\alpha$ values.

5. From the aforementioned values a new average TOC value for each particular day and for all the $R_{0}$ and $\alpha$ values was calculated, which is referred to as true ozone value (see bottom of Table 3 for the case of 5 September 2012).

6. In the next step we added $\Delta X$ values to the true ozone value of each particular day and for all the $R_{0}$ and $\alpha$ values in order to reproduce the $X_{\text {trend }}$ values. These new TOC values (referred to as $X_{\text {theor }}$ ) would have been measured if the TOC equaled the true ozone value and stray light effect for this particular instrument was described by the specific values of $R_{0}$ and $\alpha$. An example of the produced table for the same day as before is given in Table 4. 
Table 5. Pearson correlation coefficients among $X_{\text {trend }}$ and $X_{\text {theor }}$ values obtained for the case of 5 September 2012. Bold values are less than the obtained mean value.

\begin{tabular}{|c|c|c|c|c|c|c|c|}
\hline \multirow{2}{*}{\multicolumn{2}{|c|}{$\begin{array}{c}\text { Pearson correlation } \\
\text { coefficients }\end{array}$}} & \multicolumn{6}{|c|}{$\alpha$} \\
\hline & & 1.2 & 1.1 & 1 & 0.9 & 0.8 & 0.7 \\
\hline \multirow{11}{*}{$R_{0}$} & $10^{-3.3}$ & 0.985 & 0.988 & 0.987 & 0.982 & 0.979 & 0.979 \\
\hline & $10^{-3.4}$ & 0.987 & 0.989 & 0.985 & 0.980 & 0.977 & 0.978 \\
\hline & $10^{-3.5}$ & 0.989 & 0.988 & 0.983 & 0.978 & 0.976 & 0.977 \\
\hline & $10^{-3.6}$ & 0.989 & 0.987 & 0.981 & 0.975 & 0.974 & 0.977 \\
\hline & $10^{-3.7}$ & 0.989 & 0.985 & 0.978 & 0.973 & 0.973 & 0.976 \\
\hline & $10^{-3.8}$ & 0.988 & 0.982 & 0.974 & 0.971 & 0.972 & 0.976 \\
\hline & $10^{-3.9}$ & 0.986 & 0.978 & 0.971 & 0.969 & 0.971 & 0.975 \\
\hline & $10^{-4.0}$ & 0.984 & 0.975 & 0.968 & 0.967 & 0.970 & 0.975 \\
\hline & $10^{-4.5}$ & 0.962 & 0.956 & 0.956 & 0.961 & 0.968 & 0.974 \\
\hline & $10^{-4.9}$ & 0.945 & 0.946 & 0.952 & 0.960 & 0.967 & 0.974 \\
\hline & $10^{-5.0}$ & 0.942 & 0.944 & 0.951 & 0.959 & 0.967 & 0.974 \\
\hline
\end{tabular}

7. Then three different statistical tools (Pearson correlation coefficient, root mean square deviation (RMSD), Pearson's Chi-square test (CHI SQ.)) are employed in order to estimate the goodness of fit between the experimental data $\left(X_{\text {trend }}\right)$ and the theoretical values $\left(X_{\text {theor }}\right)$. This is a mandatory step so that we can identify the values of parameters $R_{0}$ and $\alpha$ which best describe the behaviour of Dobson spectrophotometer No. 118.

The Pearson correlation coefficient measures the linear dependence between two parameters, ranging from -1 to 1 . When the coefficient equals $1(-1)$ it means that the two parameters are absolutely correlated (anti-correlated) while the value 0 indicates that there is no correlation between the parameters. A detailed description of the calculation of Pearson correlation coefficient is available elsewhere (Pearson, 1920). In our case, the two parameters are $X_{\text {trend }}$ and $X_{\text {theor }}$ values. Pearson correlation coefficients were calculated for all $R_{0}$ and $\alpha$ pairs. So for each day 66 correlation coefficients (11 values of $R_{0} \times 6$ values of $\alpha$ ) (statistically significant at $99 \%$ confidence level) have been obtained. The coefficients among all the experimental days range from 0.881 to 0.998 . In order to distinguish the "good" from the "bad" results, the average value for each particular day was calculated. The coefficients which were lower from their average value for each specific day, and hence the pairs of $R_{0}$ and $\alpha$, were rejected. Table 5 shows correlation coefficients for all stray light models that were tested to fit observations on 5 September 2012. For that day, the mean value of all correlation coefficients was calculated to be 0.974 . The bold values in the table are the ones which are less than this mean value. The pairs of $R_{0}$ and $\alpha$ which correspond to those bold values were rejected.

Next, a new table calculating the RMSD between $X_{\text {theor }}$ values and the $X_{\text {trend }}$ values for all $R_{0}$ and $\alpha$ pairs for the whole range of air mass values (i.e. for all $\mu$ values) has been created. RMSD measures the "distance" between simulated values and experimentally obtained values. Actually, it represents the standard deviation of the differences between
Table 6. RMSD values among $X_{\text {trend }}$ and $X_{\text {theor values obtained }}$ for the case of 5 September 2012. Bold values are greater than the obtained mean value.

\begin{tabular}{|c|c|c|c|c|c|c|c|}
\hline \multirow{2}{*}{\multicolumn{2}{|c|}{ RMSD }} & \multicolumn{6}{|c|}{$\alpha$} \\
\hline & & 1.2 & 1.1 & 1 & 0.9 & 0.8 & 0.7 \\
\hline \multirow{11}{*}{$R_{0}$} & $10^{-3.3}$ & 46.46 & 29.24 & 16.64 & 16.38 & 22.49 & 27.04 \\
\hline & $10^{-3.4}$ & 42.54 & 25.60 & 15.32 & 17.81 & 23.84 & 27.79 \\
\hline & $10^{-3.5}$ & 38.43 & 22.20 & 14.92 & 19.40 & 25.05 & 28.41 \\
\hline & $10^{-3.6}$ & 34.25 & 19.26 & 15.39 & 20.98 & 26.10 & 28.92 \\
\hline & $10^{-3.7}$ & 30.13 & 16.98 & 16.47 & 22.49 & 26.99 & 29.34 \\
\hline & $10^{-3.8}$ & 26.19 & 15.59 & 17.92 & 23.85 & 27.75 & 29.69 \\
\hline & $10^{-3.9}$ & 22.60 & 15.17 & 19.52 & 25.07 & 28.38 & 29.97 \\
\hline & $10^{-4.0}$ & 19.55 & 15.64 & 21.11 & 26.12 & 28.90 & 30.20 \\
\hline & $10^{-4.5}$ & 17.10 & 22.81 & 27.10 & 29.35 & 30.38 & 30.81 \\
\hline & $10^{-4.9}$ & 23.06 & 27.20 & 29.39 & 30.38 & 30.81 & 30.99 \\
\hline & $10^{-5.0}$ & 24.36 & 27.93 & 29.73 & 30.53 & 30.87 & 31.01 \\
\hline
\end{tabular}

the simulated and experimentally obtained values. So it is frequently used for evaluating a model. According to Hyndman and Koehler (2006) the scale-dependent measures, as RMSD, may be used for comparing different models which are applied to the same set of data, like in our case with the different sets of $R_{0}$ and $\alpha$ values. Of course, these measures are not applicable for comparing data sets that have different scales. In order to distinguish the "good" from the "bad" results the average value for each particular day was calculated. Values which were greater than their average value, and hence the pairs of $R_{0}$ and $\alpha$, were rejected. Table 6 provides all RMSD values calculated for difference between the model and observed data. For that day, the mean value of all RMSD values was calculated 25.36. The bold values in the table are the ones which are less than this mean value. The pairs of $R_{0}$ and $\alpha$ which correspond to those bold values were rejected.

Finally, a CHI SQ. test to calculate test statistic $\chi^{2}$ for $X_{\text {trend }}-X_{\text {theor }}$ values (calculated for all $R_{0}$ and $\alpha$ pairs) has been employed. In this test experimentally obtained values are compared with theoretical values. It is actually a null hypothesis test. In our case the null hypothesis is that experimental and theoretical values have no difference. In order to decide whether or not to reject the null hypothesis the test statistic $\chi^{2}$ is computed and compared to a critical value. The determination of this critical value is based on the degrees of freedom engaged in each particular day. Values of $\chi^{2}$ which were greater than the critical value, according to degrees of freedom for each case and for $95 \%$ significance level, and hence the pairs of $R_{0}$ and $\alpha$, were rejected. In Table 7 are given the obtained $\chi^{2}$ values for the case of 5 September 2012. For that day, the degrees of freedom were 18 so for $95 \%$ significance level the critical value was 28.869 . The bold values in the table are the ones which are less than this mean value. The pairs of $R_{0}$ and $\alpha$ which correspond to those bold values were rejected. 
Table 7. $\chi^{2}$ values among $X_{\text {trend }}$ and $X_{\text {theor }}$ values obtained for the case of 5 September 2012. Bold values are greater than the obtained critical value.

\begin{tabular}{|c|c|c|c|c|c|c|c|}
\hline & \multirow[b]{2}{*}{$\chi^{2}$} & \multicolumn{6}{|c|}{$\alpha$} \\
\hline & & 1.2 & 1.1 & 1 & 0.9 & 0.8 & 0.7 \\
\hline \multirow{11}{*}{$R_{0}$} & $10^{-3.3}$ & 183.88 & 61.70 & 17.58 & 18.98 & 35.42 & 49.59 \\
\hline & $10^{-3.4}$ & 150.78 & 45.83 & 15.15 & 22.60 & 39.44 & 52.06 \\
\hline & $10^{-3.5}$ & 119.80 & 33.37 & 14.86 & 26.74 & 43.16 & 54.17 \\
\hline & $10^{-3.6}$ & 92.23 & 24.38 & 16.33 & 31.07 & 46.49 & 55.94 \\
\hline & $10^{-3.7}$ & 68.87 & 18.65 & 19.12 & 35.38 & 49.42 & $\mathbf{5 7 . 4 1}$ \\
\hline & $10^{-3.8}$ & $\mathbf{5 0 . 0 7}$ & 15.81 & 22.80 & 39.46 & 51.94 & 58.62 \\
\hline & $10^{-3.9}$ & 35.82 & 15.37 & 26.99 & 43.22 & 54.08 & 59.61 \\
\hline & $10^{-4.0}$ & 25.83 & 16.82 & 31.38 & 46.58 & 55.88 & 60.41 \\
\hline & $10^{-4.5}$ & 20.43 & 36.26 & 49.77 & 57.43 & 61.05 & 62.62 \\
\hline & $10^{-4.9}$ & 36.97 & 50.13 & 57.57 & 61.08 & 62.62 & 63.26 \\
\hline & $10^{-5.0}$ & 40.96 & $\mathbf{5 2 . 5 7}$ & 58.76 & 61.61 & 62.84 & 63.35 \\
\hline
\end{tabular}

Table 8. Scorecard of all $R_{0}$ and $\alpha$ pairs for the case of 5 September 2012.

\begin{tabular}{cccccccc}
\hline & \multicolumn{7}{c}{$\alpha$} \\
\cline { 3 - 7 } & & 1.2 & 1.1 & 1 & 0.9 & 0.8 & 0.7 \\
\hline$R_{0}$ & 0 & 0 & 1 & 1 & 0 & 0 \\
$10^{-3.3}$ & $10^{-3.4}$ & 0 & 0 & 1 & 1 & 0 & 0 \\
$10^{-3.5}$ & 0 & 0 & 1 & 1 & 0 & 0 \\
$10^{-3.6}$ & 0 & 1 & 1 & 0 & 0 & 0 \\
$10^{-3.7}$ & 0 & 1 & 1 & 0 & 0 & 0 \\
$10^{-3.8}$ & 0 & 1 & 1 & 0 & 0 & 0 \\
$10^{-3.9}$ & 0 & 1 & 0 & 0 & 0 & 0 \\
$10^{-4.0}$ & 1 & 1 & 0 & 0 & 0 & 0 \\
$10^{-4.5}$ & 0 & 0 & 0 & 0 & 0 & 0 \\
$10^{-4.9}$ & 0 & 0 & 0 & 0 & 0 & 0 \\
$10^{-5.0}$ & 0 & 0 & 0 & 0 & 0 & 0 \\
\hline
\end{tabular}

Subsequently, the pairs of the parameters $R_{0}$ and $\alpha$ are gathered in a new table, one for each particular day. The pairs of $R_{0}$ and $\alpha$ that were rejected as a result of at least one of the statistical tests were scored with 0 , while the pairs that passed all statistical tests were scored with 1 . For the case of 5 September 2012 the results are presented in Table 8.

Then, by taking into account the pairs of values that were the predominant for all the days, the values of the parameters of the Basher model best suiting Dobson spectrophotometer No. 118 have been identified. Repeating this procedure for all experimental days we get the final scorecard which is given in Table 9. In this table, row "SUM" includes the total score obtained for each value of parameter $\alpha$ while column "SUM" includes the total score obtained for each value of parameter $R_{0}$. Considering the greatest SUMS for each parameter, we conclude that parameter $R_{0}$ ranges from $10^{-3.8}$ to $10^{-3.6}$ and parameter $\alpha$ ranges from 0.7 to 0.9 . According to Table 9 the highest score obtained for all pairs of $R_{0}$
Table 9. Final scorecard for all $R_{0}$ and $\alpha$ pairs and for all experimental days.

\begin{tabular}{|c|c|c|c|c|c|c|c|c|}
\hline & & \multicolumn{6}{|c|}{$\alpha$} & \multirow[t]{2}{*}{ SUM } \\
\hline & & 1.2 & 1.1 & 1 & 0.9 & 0.8 & 0.7 & \\
\hline \multirow{11}{*}{$R_{0}$} & $10^{-3.3}$ & 0 & 0 & 1 & 1 & 2 & 2 & 6 \\
\hline & $10^{-3.4}$ & 0 & 0 & 1 & 2 & 2 & 2 & 7 \\
\hline & $10^{-3.5}$ & 0 & 0 & 1 & 2 & 2 & 2 & 7 \\
\hline & $10^{-3.6}$ & 0 & 1 & 1 & 2 & 2 & 2 & 8 \\
\hline & $10^{-3.7}$ & 0 & 1 & 1 & 2 & 2 & 2 & 8 \\
\hline & $10^{-3.8}$ & 0 & 1 & 2 & 2 & 2 & 2 & 9 \\
\hline & $10^{-3.9}$ & 0 & 1 & 1 & 1 & 1 & 2 & 6 \\
\hline & $10^{-4.0}$ & 1 & 1 & 1 & 1 & 1 & 2 & 7 \\
\hline & $10^{-4.5}$ & 1 & 0 & 0 & 0 & 0 & 1 & 2 \\
\hline & $10^{-4.9}$ & 0 & 0 & 0 & 0 & 0 & 1 & 1 \\
\hline & $10^{-5.0}$ & 0 & 0 & 0 & 0 & 0 & 1 & 1 \\
\hline \multicolumn{2}{|c|}{ SUM } & 2 & 5 & 9 & 13 & 14 & 19 & \\
\hline
\end{tabular}

and $\alpha$ is 2 . This means that no single pair of $R_{0}$ and $\alpha$ succeeded in calculating stray light effect for all experimental days. This result indicates that Basher's model has failed to quantify the effect of stray light on TOC measurements made by Dobson spectrophotometer under all conditions, and further study is needed, as also mentioned in Basher (1982) and Evans et al. (2009). However, it is also demonstrated that Basher's model is a very useful tool, and so far the only applicable method for evaluating the stray light levels present in a Dobson spectrophotometer.

Athens Dobson Station performs total ozone content measurements for air mass values up to 2.5. For that range of $\mu$, Basher model results introduce a mean underestimation of Dobson No. 118 measurements of about 3.5 DU. In Fig. 4a seasonal mean values of Dobson measurements along with satellite observations performed by Total Ozone Mapping Spectrometer (TOMS), on board Nimbus-7 and Earth Probe satellites (TOMS version 8), as well as Ozone Monitoring Instrument (OMI, OMDOAO3 version 3), on board Aura satellite, in Athens, Greece during 1991-2014 are presented. For comparison reasons, we present in Fig. 4b the ratios of Dobson raw and corrected seasonal mean values to OMI seasonal mean values for the period 2013-2014, indicatively. Ratio 1 represents the ratio of raw seasonal mean values of Dobson measurements to OMI observations, ratio 2 represents the corrected seasonal mean values, using $R_{0}=10^{-3.8}$ and $\alpha=0.9$, to OMI observations and ratio 3 represents the corrected seasonal mean values, using $R_{0}=10^{-3.6}$ and $\alpha=0.7$, to OMI observations. The Pearson correlation coefficients between the corrected daily TOC values and satellite data are slightly higher $(0.91926$ and 0.91918 for the case of $R_{0}=10^{-3.8}, a=0.9$ and $R_{0}=10^{-3.6}, a=0.7$, respectively) than the one obtained using the raw TOC values (0.91909) for the period 2013-2014. It should be men- 


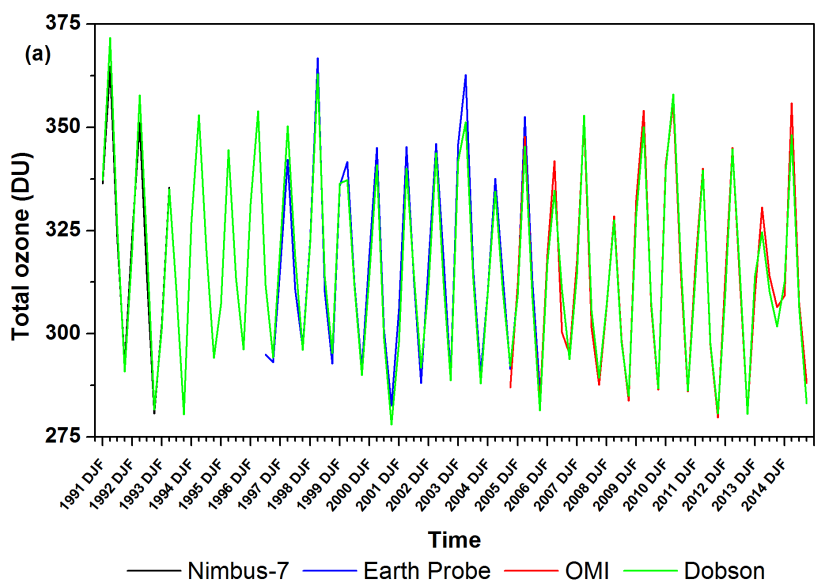

\section{Conclusion}

The main conclusion drawn from the above mentioned analysis is that the Dobson spectrophotometer No. 118 has small error on the retrieved ozone due to stray light. More specifically to the case of Athens Dobson Station, which regularly makes measurements with air mass values of up to 2.5 , a mean underestimation of $3.5 \mathrm{DU}$ (or about $1 \%$ of the station's mean TOC value) is obtained. In more detail, the parameters $R_{0}$ and $\alpha$ of the Basher's stray light model range from $10^{-3.8}$ to $10^{-3.6}$ and 0.7 to 0.9 , respectively. These values are almost equal $\left(R_{0}=10^{-3.5}-10^{-3.4}, \alpha=0.6-0.9\right)$ which were calculated about 15 years ago, when a similar check was made on this instrument (Varotsos et al., 1998). This demonstrates that the Athens Dobson instrument remains in a very good condition although it is used daily. It is therefore of great importance to stress that this TOC station may continue to be considered as the ground truth station for the satellite observations over the mid-latitude belt of the Northern Hemisphere.

Acknowledgements. This study was partly funded by the Greek General Secretariat for Research and Technology (GSRT) through the project $12 \mathrm{CHN} 350$.

Edited by: L. Lamsal

Figure 4. (a) Seasonal mean values of Dobson measurements along with satellite observations performed by Total Ozone Mapping Spectrometer (TOMS), on board Nimbus-7 and Earth Probe satellites, as well as Ozone Monitoring Instrument (OMI), on board Aura satellite, in Athens, Greece during 1991-2014. (b) The ratios of Dobson raw and corrected seasonal mean values to OMI seasonal mean values for the period 2013-2014. For details about the meaning of Ratio 1, Ratio 2 and Ratio 3 please see text.

tioned here that the seasonal differences obtained are smaller for the periods March, April, May (MAM), June, July, August (JJA) and September, October, November (SON) and slightly higher for the period December, January, February (DJF). In addition, by applying Wilcoxon's test it was found that Dobson underestimates the total ozone with respect to TOMS (Nimbus-7), TOMS (Earth Probe) and OMI by 5, 2 and $5 \mathrm{DU}$, respectively. These results, among other reasons (different spectral windows, interference from other atmospheric absorbers, differences in the spectroscopic and other parameters used by satellite and Dobson spectrophotometer), may be partially attributed to the plausible underestimation of Dobson measurements due to stray light effect.

\section{References}

Basher, R. E.: Review of the Dobson spectrophotometer and its accuracy, Report No. 13, in: Global Ozone Research and Monitoring Project, World Meteorological Organization, Geneva, 1982.

Bernhard, G., Booth, C. R., and McPeters, R. D.: Calculation of total column ozone from global UV spectra at high latitudes, J. Geophys. Res., 108, 4532, doi:10.1029/2003JD003450, 2003.

Bojkov, R. D. and Balis, D. S.: The history of total ozone measurements, the early search for signs of a trend and an update, in: Twenty Years of Ozone Decline, Proceedings of the Symposium for the 20th Anniversary of the Montreal Protocol, Athens, 23 26 September 2007, 73-110, 2009.

Broennimann, S., Staehelin, J., Farmer, S. F. G., Cain, J. C., Svendby, T., and Svenoe, T.: Total ozone observations prior to the IGY, I: a history, Q. J. Roy. Meteor. Soc., 129, 2797-2817, doi:10.1256/qj.02.118, 2003.

Chandra, S. and Varotsos C. A:. Recent trends of the total column ozone: implications for the Mediterranean region, Int. J. Remote Sens., 16, 1765-1769, 1995.

Chandra, S., Varotsos, C., and Flynn, L. E.: The mid-latitude total ozone trends in the Northern Hemisphere, Geophys. Res. Lett., 23, 555-558, doi:10.1029/96GL00305, 1996.

Christodoulakis, J., Tzanis, C., and Varotsos, C.: Standardization of the Athens Dobson spectrophotometer versus reference Dobson spectrophotometer 064, Int. J. Remote Sens., 29, 1917-1920, doi:10.1080/01431160701758707, 2008.

Cracknell, A. P. and Varotsos, C. A.: The contribution of remote sensing to the implementation of the Montreal Protocol and the 
monitoring of its success, Int. J. Remote Sens., 30, 3853-3873, doi:10.1080/01431160902821999, 2009.

Cracknell, A. P. and Varotsos, C. A. (Eds.): Remote Sensing and Atmospheric Ozone: Human Activities versus Natural Variability, Praxis Publishng, UK, 2012.

Cracknell, A. P. and Varotsos C. A.: Satellite systems for atmospheric ozone observations, Int. J. Remote Sens., 35, 5566-5597, 2014.

Dobson, G. M. B.: A photoelectric spectrophotometer for measuring the amount of atmospheric ozone, P. Phys. Soc., 43, 324-339, doi:10.1088/0959-5309/43/3/308, 1931.

Dobson, G. M. B.: Observers' Handbook For the Ozone Spectrophotometer, Ann. Int. Geophys. Year, 5, Part I, 46-87, 1957.

Dobson, G. M. B.: Forty years' research on atmospheric ozone at Oxford: a history, Appl. Optics, 7, 387-405, 1968a.

Dobson, G. M. B.: The Evaluation and Elimination of Errors in the Measurement of Total Ozone When the Sun Is Low, Memorandum No. 68.6, Atmos. Phys., Clarendon Laboratory, University of Oxford, London, 1968b.

Evans, R., McConville, G., Oltmans, S., Petropavlovskikh, I., and Quincy, D.: Measurement of internal stray-light within Dobson ozone spectrophotometers, Int. J. Remote Sens., 30, 4247-4258, doi:10.1080/01431160902825057, 2009

Komhyr, W. D. and Evans, R. D.: Operations Handbook: Ozone Observations with a Dobson Spectrophotometer, GAW No. 183, Revised 2008, World Meteorological Organization Global Atmospheric Watch, 2008.

Kondratyev, K. Y.: Radiation in the atmosphere, Academic Press, New York, USA, London, UK, 1969.

Labow, G. J., McPeters, R. D., and Bhartia, P. K.: A comparison of TOMS \& SBUV version 8 total column ozone data with data from ground stations, in: Proceedings of the XX Quadrennial Ozone Symposium, Kos, Greece, 1-8 June 2004, 123-124, 2004.

McPeters, R. D. and Labow, G. J.: An assessment of the accuracy of 14.5 years of Nimbus 7 TOMS version 7 ozone data by comparison with the Dobson network, Geophys. Res. Lett., 23, 36953698, doi:10.1029/96GL03539, 1996.

McPeters, R., Kroon, M., Labow, G., Brinksma, E., Balis, D., Petropavlovskikh, I., and Levelt, P. F.: Validation of the AURA Ozone Monitoring Instrument total column ozone product, J. Geophys. Res., 113, D15S14, doi:10.1029/2007JD008802, 2008.

Olafson, R. A. and Asbridge, I. A.: Stray light in the Dobson spectrophotometer and its effect on ozone measurements, in: Proceedings of Quadrennial International Ozone Symposium, Boulder, Colorado, USA, 4-9 August 1980, 46-47, 1981.

Pearson, K.: Notes on the history of correlation, Biometrika, 13, 25-45, 1920.

Petropavlovskikh, I., Evans, R. B., McConville, G., Miyagawa, K., and Oltmans, S.: Effect of the out-of-band stray-light on the retrieval of the Umkehr Dobson ozone profiles, Int. J. Remote Sens., 30, 6461-6482, doi:10.1080/01431160902865806, 2009.

Petropavlovskikh, I., Evans, R., McConville, G., Oltmans, S., Quincy, D., Lantz, K., Disterhoft, P., Stanek, M., and Flynn, L.: Sensitivity of Dobson and Brewer Umkehr ozone profile retrievals to ozone cross-sections and stray-light effects, Atmos. Meas. Tech., 4, 1841-1853, doi:10.5194/amt-4-1841-2011, 2011.
Scarnato, B., Staehelin, J., Peter, T., Grbner, J., and Stübi, R.: Temperature and slant path effects in Dobson and Brewer total ozone measurements, J. Geophys. Res., 114, D24303, doi:10.1029/2009JD012349, 2009.

Staehelin, J., Kerr, J., Evans, R., and Vanicekm, K.: Comparison of total ozone measurements of Dobson and Brewer spectrophotometers and recommended transfer functions, World Meteorological Organization Global Atmosphere Watch, No. 149, WMO TD No. 1147, 2003.

Tzanis, C.: Ground-based observations of ozone at Athens, Greece during the solar eclipse of 1999, Int. J. Remote Sens., 26, 35853596, 2005.

Tzanis, C.: Total ozone observations at Athens, Greece by satelliteborne and ground-based instrumentation, Int. J. Remote Sens., 30, 6023-6033, 2009.

Tzanis, C., Christodoulakis, J., Efstathiou, M., and Varotsos, C.: Comparison of the Athens Dobson spectrophotometer with world standard instruments, Int. J. Remote Sens., 30, 3943-3950, doi:10.1080/01431160902822005, 2009.

Varotsos, C. A.: Total ozone measurements over Athens: intercomparison between Dobson, TOMS (version 6) and SBUV measurements, Int. J. Remote Sens., 19, 3327-3333, 1998.

Varotsos, C. A. and Cracknell, A. P.: Three years of total ozone measurements over Athens obtained using the remote sensing technique of a Dobson spectrophotometer, Int. J. Remote Sens., 15, 1519-1524, doi:10.1080/01431169408954181, 1994a.

Varotsos, C. A. and Cracknell, A. P.: On the accuracy of total ozone measurements made with a Dobson spectrophotometer in Athens, Int. J. Remote Sens., 15, 3279-3283, 1994 b.

Varotsos, C. A. and Kondratyev, K. Y.: Ozone dynamics over Greece as derived from satellite and in situ measurements, Int. J. Remote Sens., 16, 1777-1798, doi:10.1080/01431169508954518, 1995.

Varotsos, C. A., Cracknell, A. P., Sakellariou, N. K., Katsikis, S., Chronopoulos, G., and Kassomenos, P.: On the $\mathrm{SO}_{2}$ and $\mathrm{NO}_{2}$ interferences in total ozone measurements made with the Dobson spectrophotometer No. 118 in Athens, Int. J. Remote Sens., 16, 1805-1813, 1995.

Varotsos, C., Katsikis, S., and Cracknell, A. P.: On the influence of stray-light on the total ozone measurements made with Dobson spectrophotometer No. 118 in Athens, Greece, Int. J. Remote Sens., 19, 3307-3315, doi:10.1080/014311698213993, 1998.

Varotsos, C. A., Cracknell, A. P., and Tzanis, C.: The exceptional ozone depletion over the Arctic in January-March 2011, Remote Sens. Lett., 3, 343-352, doi:10.1080/01431161.2011.597792, $2012 \mathrm{a}$.

Varotsos, C., Ondov, J., Tzanis, C., Öztürk, F., Nelson, M., Ke, H., and Christodoulakis, J.: An observational study of the atmospheric ultra-fine particle dynamics, Atmos. Environ., 59, 312319, doi:10.1016/j.atmosenv.2012.05.015, 2012b.

Varotsos, C., Christodoulakis, J., Tzanis, C., and Cracknell, A. P.: Signature of tropospheric ozone and nitrogen dioxide from space: A case study for Athens, Greece, Atmos. Environ., 89, 721-730, doi:10.1016/j.atmosenv.2014.02.059, 2014. 